\title{
Study on the Implementation of Stratified Teaching in Table Tennis Teaching of Colleges
}

\author{
Li Sun
}

University of Electronic Science and Technology of China, Chengdu, Sichuan, 611731

\begin{abstract}
Keywords: Table Tennis, Traditional, Hierarchical Teaching, Practical Situation, Application Exploration
\end{abstract}

\begin{abstract}
The development of table tennis is very important in our country. Table tennis teaching is one of the key teaching methods in colleges and universities. Compared with traditional teaching methods, it is better to use stratified teaching method in college table tennis teaching. In this paper, a comprehensive discussion of the hierarchical teaching, and the traditional teaching model to think about the problem, the full use of hierarchical teaching approach combined with the actual situation of students, stratified teaching practical application of exploration.
\end{abstract}

\section{Introduction}

The teaching mode of the hierarchical teaching is put forward by careful thinking and full practice. Under such a model, students can choose their own in the process of table tennis, so that the level of teaching is very large Follow the new curriculum to students based teaching ideas. The college table tennis teaching in the hierarchical teaching, help to improve the enthusiasm of students.

\section{The Important Foundation for the Practice of Hierarchical Teaching}

Since China entered a new era of development, the country's standards have been significantly improved. In education from the past to focus on the development of theoretical knowledge to education after the reform focus on the overall development of students and the quality of education. China's educational philosophy has undergone significant changes. This change in the objective requirements of the school's education to be reformed, do not use the traditional concept of teaching students to manage [1]. Schools to adapt to the country's teaching development, we must actively consider the new teaching methods to promote the comprehensive and healthy development of students. The policy support of the state has laid the theoretical foundation for the emergence of the hierarchical teaching. The school will inevitably apply the layered teaching to the actual table tennis teaching in order to improve the level of table tennis in these colleges and universities.

With the rapid development of society, the demand for talent is getting higher and higher, as the cultivation of talent base of the university education, in the face of such a request, the way of education must be adjusted to strive for a comprehensive and healthy development of students. Hierarchical teaching is a new type of teaching model, its pursuit of the purpose is to improve the ability of all aspects of the students, so, in such a request, the teacher in the use of hierarchical teaching mode of table tennis teaching, comprehensive Cultivate students' ability of independent innovation, group of understanding and friendship between each other, hierarchical teaching model in line with the actual requirements of society. Schools and teachers can only focus on the comprehensive ability of students in order to make more college students become the community's comprehensive development of talent. The school's teaching philosophy is only suitable for practical requirements, in order to make the school's education in an invincible position.

In modern society, the pace of the city is getting faster [2], the pressure of work is getting bigger and bigger, in the face of such life, the trend of society gradually pursue a healthy body, and in the traditional education of colleges and universities, not special Attention to the students of table tennis sports training, only focus on the knowledge of the students indoctrination, so the school does not pay attention to table tennis education, completely inconsistent with the trend of society, cultivate the talent out of the school, and can not fully adapt to the tide of the times, So the school using the 
teaching concept of hierarchical teaching so that the school can cultivate more talent to adapt to the rhythm of society, more attention in the table tennis learning to get a comprehensive development [3], the only way, the school trained personnel In order to develop in such an environment better.

\section{Implementation of the Important Role of Hierarchical Teaching}

Effective hierarchical teaching fully embodies the education of people-oriented teaching ideas, and promote the process of quality education gradually move forward. The implementation of the new curriculum standard [4], so that innovative hierarchical teaching model has been effectively carried out, this model to promote students in the school can be healthy and positive development, education, student-oriented, such a hierarchical teaching in the teacher's full The use of which, effectively establish the concept of the formation of students' self-learning, students in the table tennis learning process, their own shortcomings and advantages will have a certain understanding, to promote students to take the initiative to think about their own learning problems, To promote students in each subject of learning can take the initiative to think about the problem, improve students' academic performance, so that students in the table tennis after the hierarchical teaching, the gradual self-learning [5], the teacher in the table tennis In the teaching, the hierarchical teaching mode is conducive to the students to fully improve the ability to self-reflection, according to the survey, $80 \%$ of students in the table tennis after learning, for learning problems can be self-thinking to solve problem. So that students in the table tennis learning to take the initiative to use their own knowledge to solve the problem, not everything must rely on the teacher, they will not take the initiative to think, students in school learning, take the initiative to solve the problem can deepen the students The impression of this problem, students in the next face of such a problem, you can do a good job of their own solution. Moreover, students in the independent solution to the problem, can effectively improve the students' self-confidence in learning, students will be used to solve the problem of independent way, gradually develop a good habit of self-learning. The concept of teaching under the new curriculum is that students are the fundamental of education, pay attention to the cultivation of students' ability, so that students in the process of learning to be comprehensive development.

In the college table tennis teaching in the use of hierarchical teaching, the teacher's level of physical education have a certain understanding, so that teachers can know where the difficulties of breaking the students. This kind of hierarchical teaching method allows students to improve the table tennis, he said, a very good student and a non-sports students to play table tennis together, the contradiction between the two students will Very big, the first good sports students will think that such a table tennis teaching is really boring, and gradually on the teacher's teaching to take a negative resistance attitude is not conducive to the improvement of teaching level, poor sports students will feel very shame [6], and even such teaching will combat the self-confidence of college students, not only affect the students' knowledge of sports knowledge, and even affect students to other subjects of learning. So that two people will not actively carry out sports learning, the health of the body will not be higher than the students have been learning. In the hierarchical teaching mode, this problem does not exist, first of all, the teacher will have a preliminary understanding of the results of the students' sports, such a hierarchical teaching mode of the students of the sports are comparable , Such a poor table tennis students can stimulate each other each other, table tennis learning atmosphere will be very good, students in the mutual incentive to always adhere to the table tennis learning, so that the effective exercise of the students in the body, So that students in the school's life has learned the knowledge of the exercise of the body, and for the table tennis skills better students, in mutual cooperation with each other, can more understanding of their own problems, find each other's advantages, so that students The psychology of learning is more intense, students will actively carry out the study of sports knowledge, and actively exercise, so as to promote the students in the teaching of the body to maintain a healthy state.

In the tiered teaching, students' enthusiasm for table tennis is very high, so that different levels of students are able to carry out effective table tennis learning [7], students in the learning process of mutual encouragement and mutual competition will allow students Of the growing interest in 
learning, such a development situation, the gradual interest of the students will gradually let the students fall in love with sports training, in the hierarchical teaching mode subtle students' lifelong sports awareness gradually formed The For example, if a student in the table tennis learning has been very talented, because there is no opponent, students can only practice in the holidays, so that with the gradual increase in learning pressure, the holidays will be less and less, Students do not want to study the boring table tennis, students have thought to give up such a hobby, however, the school's hierarchical teaching model began to practice in the teaching of table tennis, after stratification, students find in the class The same love of table tennis friends, the difference between the two technical level is not high, so that two people each time in the study have a very fun feeling, students never thought to give up the sport, and has been In the very good conduct of the sport, insist on learning every day. This kind of habit can make the students' lifelong sports standard effective implementation and promote students in the future development of lifelong sports.

\section{The Practical Application of Stratified Teaching in Table Tennis Teaching in Colleges}

In the specific application of hierarchical teaching, the teacher should first have a good understanding of the level of students' table tennis, so that the teacher can make a good teaching of the students in the course of teaching, if the teacher is simply The assessment of the performance of the students stratification of the students, it is easy to lead to the level of each level of students is very uneven ability, such a hierarchical teaching is a failure of teaching [8], will be serious To dispel the enthusiasm of students to learn, and, in the hierarchical teaching, this unscientific stratification will also allow students to lose confidence in this teaching model is not conducive to the comprehensive development of hierarchical teaching. Only the teacher to assess the physical ability of students, students of the scientific stratification, students in such a hierarchical teaching, the full experience of the table tennis learning to bring the relaxed and happy, students can effectively improve their own on this The enthusiasm of the study of the study, and then the students in the future study of active participation in table tennis learning, students to learn the active participation of the sport, the level of students will be in such active participation gradually improve, so as to improve the school Overall sports level.

Teachers need to pay attention to is that in such a hierarchical teaching must highlight the student's dominant position, the teacher himself only served as the mentor of education [9], so that students in the cooperation of each other to think about their own problems, the teacher as long as the Students in the loss of confidence or feel very depressed when the students to effectively encourage students to establish confidence in the negative psychological distress, the teacher in the process of guidance, the students to sum up and correct the problem in practice to guide the students Table tennis knowledge, the saying goes, the theory is only a full combination of practice, in order to play its great guiding role, the teacher can be in the student's common cooperation so that students practical application of theoretical knowledge, which can fully deepen the students The deep impression of this theoretical knowledge, the students have a very good learning, the appropriate role of teachers to guide students to conduct a comprehensive and comprehensive ability to develop.

In the teaching of the stratification, the teacher should examine the question of the mutual communication between the students, carefully observe and prevent the negative thoughts of the students from influencing others. When the students are thinking that they are not conducive to the study of the sport, To carry out active guidance [10]. For example, in colleges and universities, physical education teachers to stratify the teaching practice of students, but a very bad sports students every time in the practice of failure are very frustrating, and finally see the ball hit a very good group of students Time, involuntarily feel very sad, I thought, how can I so stupid, so in the next activity has always been weak and unable to look like, he looks like the next side of the students infected, next to the students do not consciously think, I play bad, or do not practice, how to practice are useless. Later, the teacher came back, the teacher carried out their very careful guidance, and finally dispelled their negative thoughts, gradually began to very hard to practice hard. In the tiered teaching, the emotional infection is very important, the teacher should actively observe, 
to dispel the negative thoughts of students, and fully improve the enthusiasm of students in sports, to promote students in the future development of life-long physical training, improve the national youth Overall health level.

\section{Conclusion}

In summary, in the college table tennis teaching in the implementation of hierarchical teaching methods, in line with the state promulgated policy, fully promote the students to learn table tennis enthusiasm, is conducive to the development of table tennis in the wide range of students, Teachers to stratify the teaching methods of students, can effectively develop the students' ability to improve the school's teaching level, cultivate the concept of life-long movement of students, to promote students in the future development of life in life.

\section{References}

[1] Han Fei. College table tennis club teaching model in the effective application of layered teaching method [J]. Contemporary Sports Science and Technology, 2015, 05: 92-93.

[2] Lin Zanjun. College table tennis teaching in the implementation of stratified teaching new ideas to explore [J]. Youth Sports, 2015, 09: 80-81 +17.

[3] Yang Zhaqi. Stratified teaching in college public sports table tennis teaching application research [J]. Contemporary sports science and technology, 2015, 26: $111+113$.

[4] Wei Sheng. How to implement hierarchical teaching in college table tennis teaching [J]. New West (theoretical), 2013, 19: $159+126$.

[5] Gu Dexiang. Study on hierarchical teaching of ping-pong elective course in colleges and universities [J]. Journal of Nanjing Institute of Physical Education, 2008, 01: 74-76.

[6] Wu Cuifen. Stratification theory in the use of college table tennis teaching [J]. Journal of Zhengzhou Institute of Aeronautical Industry Management, 2012, 04: 194-196.

[7] Wang Shan. Stratified teaching model in college table tennis teaching application theory analysis [J]. Neijiang Technology, 2012, 11: $61+51$.

[8] Wang Bo. In the ordinary college table tennis teaching to carry out hierarchical teaching effectiveness analysis [J]. Journal of Chifeng University, 2016,19: 201-202.

[9] Lu Xiaoxia. "Layered teaching method" in the college table tennis teaching experimental research [J]. Sports Science and Technology, 2016 (05).

[10] Chen Qiuxi in the table tennis teaching in the implementation of hierarchical teaching [J]. Contemporary Sports Science and Technology, 2013, 35: 60-61. 